\section{ON ANKYLOSTOMIASIS.*}

By Surgen-Liedtenant-Colonel OSWALD BAKER, I.M.S.(RETIRED).

ANkyLostomiasis is a disease caused by a leech-like bloodsucking parasite which infests the small intestine. I firmly believe that ankylostomiasis is productive, both directly and indirectly, of far greater mortality than the vast majority of medical men have any conception of. The large number of deaths ascribed to unknown causes, the heavy mortality attributed to general dropsy and debility, and the great loss of life occurring among paupers found dying in the streets in tropical towns, I am convinced, were in the past and are to-day in no small measure due to ankylostomiasis.

There are few things more remarkable in the whole history of tropical medicine than the failure to realize and the reluctance to admit, on the part of many medical men, the injurious tendency of an invasion of the body by the parasite which gives rise to ankylostomiasis. In support of this statement, I would point to India, where the parasite in question-the ankylostoma duodenale-was discovered in 1879 , when McConnell found it whilst making necropsies in Calcutta. He seems to have regarded this blood-sucking parasite in the light of a pathological curiosity, and, even as late as the year 1892 , he wrote:

I maintain it has yet to be shown that the presence of this parasite gives rise to a specific disorder to which the term ankylostomiasis can be applied.

McConnell's discovery attracted but little notice, and was soon lost sight of. Eight years later-in 1887-the parasite was again found at necropsies made in Madras. There is, however, nothing on record in the medical press of India to show that the ova of this parasite had been identified in the dejecta until the following year. when attention was called in the columns of the Indian Medical Gazette by a Bengal surgeon stationed in Burmah to the serious nature of ankylostomiasis. This officer pointed out that the parasite was extremely prevalent, and produced great mortality ; also that it was the cause of much of the gaol debility seen in prisons, a disease which at that period was a veritable bête noire to gaol administrators; he, moreover, advised that the dejecta of all patients suffering from anaemia, debility, or dropsy of obscure origin should invariably be searched for ankylostoma ova. The communication in which these views and observations were embodied received very limited notice, and was, apparently, soon altogether forgotten. The next occasion in which life was infused into the subject was when Giles, who had been investigating the nature of kala-azar, made the astonishing announcement that this disease was, in his opinion, simply ankylostomiasis occurring in a malaria-stricken district. From this period ankylostomiasis has repeatedly engaged the attention of Indian medical officers, but it has not yet received in India more than a fraction of the consideration its importance demands. Only a little more than a year ago, in consequence of the prevalence of so-called gaol scurvy, a term applied to denote a condition of swollen gums associated with anaemia, amongst the convicts in a certain prison, an inquiry into the matter revealed that the disease in question was ankylostomiasis. Thymol was then obtained and used, when, according to the superintendent, Dr. Reilly, all the men recovered, some being saved, as it were, from the grave.

Nomenclature.

The parasite of ankylostomiasis, to which many synonyms have been given, is called by some observers ankylostomum duodenale, but the majority of writers use the term ankylostoma. Etymologically speaking the latter is correct, and, as the same word should if possible be employed to denote the same parasite, it is advisable. I think, to adhere to the term ankylostoma when speaking of a single parasite, and ankylostomata when referring to more than one. The use of the abbreviated words "ankylostome "and "ankylostomes" is convenient and seems unobjectionable.

\section{History.}

Although Sandwith of Cairo is of opinion that the ancient Egyptians suffered from ankylostomiasis, no reference to the parasite of the disease has been found in the writings of mediaeval times. Our knowledge of this entozoön dates only from 1838 , when Dubini, of Milan, detected it in the intes. tines at a necropsy. The parasite was discovered in * Being part of a lecture on Tropical Anaemia delivered at the London School of Tropical Medicine.
Egypt in 1847 , by Bilharz, and Greisinger, who was working with Bilharz, came to the conclusion it was the sole cause of the anaemia which was. at that time, affecting one-fourth part of the entire population of Egypt, known as Egyptian chlorosis.

In 1879 a disastrous outbreak of anaemia, of a progressive and fatal type, took place among the thousands of labourers employed in the constructon of the St. Gothard tunnel, which was pronounced to be ankylostomiasis. But then, as now, sceptics existed who attributed the anaemia to insanitary surroundings, want of light, and defective ventilation, causes which had, until then, been considered adequate to account for the anaemia very prevalent among miners and bricklayers, in different parts of Europe. From this period, however, ankylostomiasis has received notise in treatises on medicine, and to-day, although the disease has been subject to much neglect, and is still, in some quarters, discredited. I do not think any unbiassed man of ordinary intelligence, who studies the overwhelming mass of evidence which has been produced, can any longer doubt that ankylostomiasis is one of the most prevalent and fatal maladies which exist in the tropics.

Until quite recent times the anaemia of the tropics, owing to the prevailing ignorance of ankylostomiasis, was attributed to beri-beri, malaria, and general dropsy, or debility, of uncertain origin. But modern research has thrown a flood of light on this question and has solved the problem of tropical anaemia. Its revelations demand that this special anaemia of the tropics, due to the ankylostoma, shall no longer be ascribed to beri-beri with its well-known clinical signs, nor to malaria with its plasmodium malariae; nor to general dropsy, nor debility, but that it must, when the patient suffering harbours ankylostomes, and has no other demonstrable disease, be attributed to its rightiful cause, ankylostomiasis.

\section{Distribution.}

Our knowledge of the geographical distribution of ankplostomiasis is far from complete. The disease is believed to exist interruptedly over about three-fifths of the habitable globe, between $50^{\circ}$ latitude north, a chart line which passes through the north of France, and $30^{\circ}$ south latitude. So general is supposed to be its prevalence throughout the tropics that an inquiry in a locality where its existence was undetermined, which yielded negative results, would be of great interest to students of geographical pathology.

\section{Prevalence and Mortality.}

Although ankylostomiasis exists over so large an area of the earth's surface it is far more common in some places than in others. The degree of prevalence naturally depends upon conditions favourable or otherwise to the existence of the parasite which produces it. Amongst agriculicural races living in warm climates, who pay no regard to cleanliness and keep no sanitary observances, who carry food to their mouths with unwashed hands and leave their excreta on the ground around their dwellings, ankylostomiasis flourishes exceedingly. Under conaitions such as these, which obtain in a pre-eminent degree in certain parts of Egypt and India, the ankylostoma duodenale reigns supreme. The parasite is found in 90 per cent. of all necropsies made at the Kasr-elAini Hospital, Cairo; Dobson has reported that he found the worm in the dejecta of 454 out of 547 immigrants brought from different parts of India for employment on the tea gardens of Assam; Daniels noted its presence in 52 per cent. of his large number of carefully-made necropsies in Demerara ; and Dr. Giffard, of the Madras Hospital, informs me that in necropsies he, much more often than not, finds this ubiquitous tropical parasite.

Of the mortality caused by ankylostomiasis no reliable estimate can be given. As I have already pointed out, it is, I believe, the immediate and only cause of many of the deaths set down to general dropsy and debility, and also of those attributed to unknown agencies; but the mortality of which it is a contributory factor and indirect cause far outweighs, in my opinion, that due to its direct effects. Not only may it complicate all other maladies, but, by producing anaemia and disorders of the digestive functions, it lowers the natural vitality of the body, and thereby renders its subjects more receptive of and less able to cope with the many diseases of a fatal character to which mankind in the tropics is exposed. Looked at from this point of view, the enormous mortality it indirectly causes can hardly be exaggerated. In giving his opinion on this question, Dr. Thornhill, of Ceylon, states that the more he reflects on his own experience and the more he reads of the experience of others 
the firmer does his conviction become that the ankylostoma duodenale is the greatest enemy of the human race in the tropics.

The objection to the view that ankylostomiasis is a serious disease rests on two facts: First, that its parasite is widely prevalent in the body of man, and does not, in the majority of cases, do any appreciable harm ; and, secondly, that very often in death from ankylostomiasis few or no ankylostomes are found on necropsy. But both these objections are fallacious and are easily overcome. The fact that ankylostomes, when present in only small numbers, are generally harmless is in no way opposed to the equally well-known circumstance that when a severe infection takes place it is often fatal, or it produces such extreme anaemia that recovery becomes impossible. An invasion of parasites cannot be compared to an attack of a specific contagious fever, wherein the germs conveying the disease undergo rapid multiplication in the body. An infection with ankjlostomes is a purely local trouble, and, if the infection is slight, it may produce no symptoms and do no harm, for these parasites do not multiply within the human body.

With reference to the absence, in large numbers, of the parasite at the necropsies of persons dead of this anaemia, it must be borne in mind that ankylostomes, like other parasites, require food, and without it they must die. They obtain food from the blood of their hosts, but when the host has become so reduced by anaemia that his blood serum bears a resemblance to water, the parasites are no longer able to subsist on it, and deprived of the pabulum which is essential to their existence, they die, drop off the intestine and are carried away to be expelled with the dejecta. It is true that in some instances enormous numbers are found on necropsy, but in these severe cases it is possible that fatal anaemia has resulted before sufficient deterioration of the blood plasma to starve the parasites to death has occurred. In fatal haemorrhage as many as $3,000,000$ red cells may be found in a cubic millimetre of blood, whereas in death from slow progressive anaemia the number becomes reduced to $1,000,000$ or less.

There is another reason: Although some parasites are said to live as long as their hosts, such is not the case with ankylostomes, in which the limit of life is set down at five years. If this is the maximum duration of their lives, the presumption is that few reach that age. Man may live until he is 10o, but he seldom does. Consequently in cases where reinfection is avoided the parasites will in due course disappear.

These considerations are, to my mind, amply sufficient to explain the fewness, or even entire absence, of parasites sometimes found on necropsy. In severe infections, where death is not long delayed, they are seen in hundreds and thousands.

\section{Infection.}

How does the parasite gain entrance to the human body? It was at one time widely held that infection was acquired through drinking water containing the embryos, and this view is not without supporters at the present time. On what this hypothesis is founded it is difficult to say; it is presumably based on inference and analogy, and not on carefully conducted observation or experiment. As far as can be judged from the data available, infection is seldom acquired in this way. Giles, a most capable observer, has shown that the embryos will not live in water, and Sandwith states that when embryos are placed in wells or stagnant water they soon sink to the bottom. Giles, moreover, whose writings have contributed largely to our knowledge of the parasite's life-history, when working in an ankylostomiasis-stricken district, examined 56 specimens of water drawn from local sources without finding more than one embryo in the whole of his specimens, and that was of a doubtful species of worm. In his paper on ankylostomiasis, read before the International Medical Congress a few years ago, Sandwith stated that of 402 cases of the disease of which he had notes no less than 310 , that is, more than three-fourths, occurred in patients between the ages of 20 and 40 ; and Daniels, although he found the parasite in 52 per cent. of ail necropsies, only detected it in 20 per cent. of children. If drinking water were the chief, or a frequent, source of infection, the disease would inevitably have a more uniform distribution in regard to age. In view of these considerations the waterborne theory of infection must I think be given up.

By glancing at the life-history of the paragite a more correct appreciation of the matter can be gained. The ova are discharged, in myriads, with the dejeeta, and, under favourable circumstances, yield embryos in from one to two days. This phase of development takes place only outside the body, because exposure to the oxygen of the atmosphere is essential to its accomplishment. These embryos, when they gain entrance to man, quickly grow into mature parasites.

Now, the inhabitants of countries wherein ankylostomiasis is very prevalent are, for the most part, tillers of the soil, and generally live in overcrowded villages where sanitation is unknown. They have no latrines, and ease themselves anywhere, often close to their dwellings; they are dirty in their persons, and eat food with their hands, which are unwashed, and sometimes soiled with earth containing embryos. Furthermore, some races of men occasionally eat earth. The Egyptians are much given to geophagism, or earth-eating; they seem to believe that Nile mud, so valuable to their fields, may be beneficial to their bodies. Sandwith states that Nile mud, possibly taken from the banks of the river where pollution with excrement is common, is, on certain festive occasions, handed round the streets. Where such conditions prevail it. cannot be surprising that nearly all the inhabitants become infected with ankylostomes. The majority of observers maintain that infection arises under the circumstances described.

In 1898, Dr. Looss, of Cairo, asserted that ankylostoma embryos entered the body through the hair follicles of the skin. He states he became accidently infected in this way, and that, in due course, ova appeared in his faeces. To prove his case, he placed some lively embryos on the leg of a boy, about an hour before the limb was amputated for disease. On the removal of the diseased limb he made sections of that portion of the skin selected for the experiment, and found many of the hair follicles packed with embryos. Giles, who saw Looss's specimens, has no doubt that infection can take place through the skin. Manson, on the other hand-who thinks it quite natural the larvae should, under such circumstances, seek shelter in the hair follicles-is not at present prepared to endorse Looss's views. The question must remain an open one until more convincing proof has been adduced.

Symptoms.

The earliest symptoms of ankylostomiasis are not often seen because patients seldom apply for treatment until they are anaemic and incapacitated for their daily work. At first, there is epigastric discomfort and pain, with a capricious appetite, and then anaemia; as the disease advances so do these symptoms become more severe, until the patient loses all desire for food, and presents the wellknown signs of pronounced anaemia.

In addition to the chalk.white pallor of the nails and all visible mucous membranes, the empty pulse and cardiac distress, the mental and bodily apathy, all of which are marked features, oedema arises, first in the eyelids - not in the legs as in beri-beri-and subsequently extends to the entire body. Associated with this general oedema there is usually slight albuminuria, marked mental failure, and great drowsiness. When this stage is reached the case is generally hopeless, and death from asthenia soon ends the scene.

If other diseases complicate the disorder the symptoms noted will not be seen in this pure form. Excepting for eosinophilia-a common occurrence in helminthiasis-the blood presents no features special to the disease. In the early period it is of a protopathic type, with from 3,00o,oco to $4,000,000$ of red cells in the cubic millimetre, but towards the termination of a fatal case, setting aside the colour index, which is always reduced, and except for nucleated red cells, which are seldom found, it shows the character of pernicious anaemia, and gives a blood count of about $1,000,0$ oco. Rogers states that the relatively low colour index of the blood is sufficiently marked to furnish a means of diagnosing ankylostomiasis from malaria, wherein this reduction is slight. Possibly the presence of eosinophilia, by excluding a disgnosis of nncomplicated malaria, would furnish useful information. Daniels has sometimes found the eosinophile leucocytes constitute over 20 per cent. of all white cells present.

In the evacuations of the patient there will occasionally be found dead ankylostomes, confirming, in a measure, what has already been said regarding the disappearance of these parasites from the body; and if a minute fragment of faeces be stirred with a drop of water on a slide, and placed under the microscope, the characteristic ova of the ankylostome will be readily seen. Once recognized, they can never be mistaken by a careful observer.

\section{Post-mortem Appearances.}

On necropsy, all the organs are found extremely bloodless. 
On the inner surface of the small intestine, between the second portion of the duodenum and the ileum, a situation, as Daniels has pointed out, which corresponds with alkalinity of the bowel contents, numerous, or a few, ankylostomes will be found adherent to the wall of the gut; or, if the parasites have already dropped off, ecchymoses, not larger than a fleabite or split pea, having pale central points, will be visible. At the necropsies of eighteen patients dead of uncomplicated ankylostomiasis, to whom no vermifuge had been administered, the number of parasites found by Sandwith was as follows: In nine of the bodies, from $I$ to 50 ; and in the remaining nine, from 170 to 863. Ernst, of Cologne, has reported a count of 2,768 at the necropsy of a brickmaker. The little nematodes, being sometimes half buried in the mucosa, and covered with tenacious mucus, require very carefully looking for, otherwise they may be missed. Occasionally small blood cysts are found in the submucosa, con. taining one or more parasites. Fatty degeneration of the heart, liver, and in a lesser degree the kidneys, always occurs ; the liver, from fatty changes, sometimes floats when placed in water. In the peripheral cells of the liver lobules there is found, in a very finely-divided state, bright orangezellow pigment, which, owing to the fatty condition of the organ, may easily be overlooked. Dr. Yates reports that in a case of ankylostomiasis, where thousands of parasites were present, which recently came to necropsy at the Johns Hopkins Hospital, Baltimore, there existed, in addition to yellow pigment, necrosis of the hepatic cells surrounding the intralobular vein, not the peripheral cells; he also noticed that the mucous membrane of the small intestine was more or less necrosed, and that its basal layer was infiltrated with eosinophiles in enormous numbers.

In view of the marked changes found in the liver, the question of the ankylostoma being capable of producing toxin which has haemolytic and other destructive properties must be briefly considered. Some observers firmly maintain that such is the case, and to support their veiws appeal to the analogous action of the bothriocephalus latus, which although not a blood-sucking parasite, generates a blood toxin which causes profound anaemia. They point out, moreover, that the presence of such a toxin would serve to explain the ocourrence of death in those cases of ankylostomiasis wherein but few parasites are found in the body on necropsy. Furthermore, Calamida, a German observer, claims to have proved that certain other entozos undoubtedly produce toxins which not only possess active haemolytic powers, but are positively chemiotactic as regards eosinophile leucocytes. But if the opinions I have advanced on the sequence of events in ankylostomiasis are sound, the pathology of the disease, apart from the necrosis of the liver cells, is already sufficiently clear. That true haemolysis takes place is not yet conclusively proved, for the presence of yellow pigment in the liver, on which this view is based is not, as Stockman has shown, a sine qua non of haemolysis in the strict sense of the word. To explain the necrotic changes in the liver, the presence of a toxin seems necessary, but it has yet to be established that this morbid condition is a constant, or even frequent, feature of ankylostomiasis.

Prevention and Treatment.

The means of prevention of ankylostomiasis are fully expressed by the word "sanitation." It has been shown that the ova of the parasite will not develop into embryos unless the dejecta containing them are exposed to the oxygen of the atmosphere; consequently all that is necessary to arrest the spread of and stamp out the disease is to prevent this exposure taking place by burying the excreta. But, simple as the remedy is, the difficulties of applying it, without an Act of the Legislature making burial compulsory, are, in my opinion, insurmountable. It is, I think, the duty of sanitary officers to do all in their power to secure the compulsory introdtuction of some simple system of village sanitation whereby ignorant villagers will no longer be suffered to polIute their dwellings and poison themselves with their own excrement. But to obtain the necessary legal authority a good deal of preasure must be brought to bear on the executive, and until medical men themselves fully realize the fatal nature of ankylostomiasis they are unlikely to convince others that village insanitation is productive of such heavy mortality from that disease. (Bandwith has pointed out that solar heat destroys the ova and kills the embryos, provided exposure is thorough and prolonged.)

For the treatment of ankylostomiasis there is no vermifuge comparable to thym $\mathrm{ll}$. Three doses of the drug are generally given on the same day, at intervals of either half an hour or some hours. If after four or five days ova are still found in the dejecta, the thymol should be repeated as at first. This plan of treatment should be continued until all the parasites are expelled. The dose of thymol as a parasiticide is from 10 to $60 \mathrm{gr}$., according to the views of different men. The maximum dose, if used at all, should be reserved for fairly robust patients, while not more than 10 gr. should be given for a dose to those who are very, ill or much advanced in years.

It can be administered in rice paper or stirred up in water. A good plan is to keep a solution in spirit of a definite strength, and pour the prescribed dose, at the time of giving it, into $2 \mathrm{oz}$. of water, which will release the thymol in a finely-divided state.

In using thymol the same precautions in regard to food and purgatives should be taken as when using other anthelminthics. The physiological effects of thymol closely resemble those of carbolic acid, and in cases of ankylostomiasis admitted into hospital in a prostrate state it is sometimes advisable, before administering the drug, to improve the patient's condition by a short course of digitalis and judicious feeding.

Time has not permitted me to enter more fully into the many and varied features of this disease, but I venture to hope sufficient has been said to secure for it your earnest and serious consideration. Treated early ankylostomiasis is easily cured, but neglected it tends to a fatal issue. Therefore the dejecta of all persons who are received into hospitals, gaols, and asplums in the tropics should be searched for the ova of the parasite; and the diagnosis of no tropical disease associsted with anaemia should be considered complete until this investigation has been made, in whatever country the person suffering may come under observation. If the precaution to examine the evacuations of the patient who became the subject of a necropsy at the Johns Hopkins Hospital had been taken, his life would doubtless have been saved, whereas he died of anaemia with his disease unrecognized.

No clinical examination of a patient living in a tropical country where parasiticism is such an important etiological factor in disease can be deemed adequate which does not include a microscopical study of his blood and dejecta.

\section{TRYPANOSOMIASIS ON THE CONGO.}

By PATRICK MANSON, C.M.G., M.D., LL.D., F.R.S. Medical Adviser, Colonial Office and Crown Agents of Colonies.

THE publication of the case of trypanosomiasis alluded to in the columns of the BRITISH Medical Journal some month ago, and at present under my care in the wards attached to the Tropical School at the Albert Docks, has been delayed intentionally, pending developments. Meanwhile I have received information about a similar case, also a lady, and whose infection was also acquired on the Congo. As this second Congo case presents several features of a suggestive character, both as regards the manner in which the infection was acquired and also as regards the symptomatology, I have thought it well to bring it forward, although the information about it is very incomplete, in the hope that by calling attention to the points I refer to further information bearing upon them may be elicited.

History. - On July i7th, roor, a lady, aged 40 , consulted me about a fever from which she had been suffering from time to time and which was invariably preceded and accompanied by an erythematous rash on the face and brunk. The fever, she informed me, recurred with regularity about once in ten days: each attack lasted three days, and was followed by seven days of complete apyrexia. Rigor was not a prominent symptom. The erythema occurred in spots and patches varying in size from an inch in diameter to a patch $\mathrm{r}$ ft. across. Usually they presented a ringed appearance. The erythema subsided with the temperature. The patient in formed me that she had resided for two terms, of two years and one year respectively, on the Conge. It was during the last of these that the disease developed. Both she and her husband dated her illness from the middle of rgoo, and attributed it to a bite on the foot. What inflicted the bite they did not know but believed that it was an insect. The foot swelled and must have given considerable trouble, for "boracic lotions were used to take down the swelling." Two or three days after being bitten she sickened with what her husband described as a " big fever" of two months' duration. The temperature did not reach the absolute normal for quite three months. Erythema was a feature of the fever from the commencement. Being pregnant at the time she left the Congo for England. Throughout the voyage she suffered from fever. She arrived in England in April, roor. A week later she was confined prematurely of an eight routh; chi'd. Since the confinement, and until 